electric magnitudes at power frequencies, with a range of sensitivities and an accuracy which it would be very difficult to obtain by other means."

N. E. Dorsey summarises and discusses, in a paper of general interest (No. 10), the results of the most important determinations of the velocity of light, of the ratio of the electromagnetic to the electrostatic unit of electricity, and of the velocity of propagation of Hertzian waves. He concludes that experiment confirms modern electromagnetic theory in regarding the results as being determinations by three different methods of one and the same quan. tity, and gives 299,792 kilometres per second as the most probable value. Dorsey directs attention to the apparently systematic decrease in the values obtained for the velocity of light during the last fifty years, but does not agree with Gheury de Bray that the fact indicates an actual decrease in the value of $C$, for, quoting from comments on the subject which appeared in these columns (NATURE, 120, 594, Oct, 22, 1927): "An absolute change in the velocity of light ... could scarcely obtain acceptance unless supported by much more decisive observational material."

\title{
Engineering Methods in Optical Manufacture
}

$\mathrm{M}^{\mathrm{s}}$ R. WILLIAM TAYLOR'S valuable presidential address on October 28 to the Institution of Mechanical Engineers gave a very illuminating résumé of the modern methods of photographic lens manufacture in use in the famous Leicester factory of Messrs. Taylor, Taylor and Hobson, Ltd., and of a number of original methods which are the fruit of his own genius as an engineer. Amongst these innovations may be mentioned the tubular cutter for lens blanks, the annular carborundum wheel for roughing, improved fine-grinding and polishing machinery with an automatic supply of rouge and water, and special machines for edging. The description of these, published in the Proceedings of the Institution, will well repay reading by all interested in methods of optical manufacture or allied processes.

It is at first sight surprising, as the address hints, to find very primitive methods still surviving in some optical workshops, and this in spite of all that modern engineering and mass production methods can achieve. It is no slight on Mr. Taylor's originality to remind ourselves that Robert Hooke suggested, nearly three hundred years ago in the preface to his "Micrographia", the use of the grinding wheel on an inclined adjustable axis for producing curves of any required radius, for there is a long step between the geometry of the method and its successful application in practice. It has to be recognised, too, that operations and machines which can be worked successfully in a large factory for more or less continuous production are beyond the scope of a smaller concern where the optical work, though important, does not justify the installation of any but essential machinery.
The logic of the mass production thesis is the concentration of production in a few centres; the problem which it brings is the fair distribution of the wealth created, both in the form of goods and leisure. The mainspring of the whole movement in mechanisation is, as Mr. Taylor implies, the everpresent urge to overcome physical limitations of all kinds. In itself, this is one of the most excellent of human aspirations, and the spirited defence of mechanisation which forms the closing part of the address is unanswerable, provided that mankind is educated up to the duties which its privileges involve. But since our ethical and political development is so slow, we may sometimes tremble lest over-quick rationalisation should produce a condition beyond our power to control.

Apart from considerations of this kind, it is unlikely that optical manufacture has yet reachod a finally definitive stage; we may speculate, however, as to whether future advances will consist in a slow progress in matters of detail, or whether some leading invention will render possible the production at will of non-spherical surfaces of prescribed form and optical accuracy. This latter is, indeed, no new problem. Food for thought will be found in the theoretical work on the subject dating from the time of Descartes, and the practical experiments of Fraunhofer, Bessemer, Parsons, and others. Optical accuracy has not been attained, but our command over physical processes is growing, and grinding is not the only method of producing surfaces of required form.

Mr. Taylor has shown us that progress can still be made by courageous attack, and we should ask for nothing better than to venture forward.

L. C. M.

\section{New Gaseous Lamp}

$\mathrm{O}^{\mathrm{N}}$ November 15 at a special meeting of the Illuminating Engineering Society held at the Wembley Laboratories of the General Electric Com. pany, Ltd., Mr. C. C. Paterson read a paper on luminous discharge tube lighting. He pointed out that the current through the discharge tubes does not follow Ohm's law. It varies in a complicated way with the pressure of the gas inside the tube, the apparent resistance diminishing as the current increases.

The new discharge tubes were suggested by Pirani in Berlin and by the General Electric Company of America. They make use of the experimental fact that if the cathode is heated to a temperature at which it will emit electrons freely, the voltage fall at the cathode will be greatly reduced and so large currents can be passed without serious sputter-

No. 3291, VoL. 130] ing taking place. The electrodes of these tubes or 'gaseous lamps' consist of alkaline earth oxides which can be heated electrically like small filaments. With the use of these electrodes the cathode fall is only about twenty-five volts. The current therefore can be thirty or even a hundred times as large as that obtainable with ordinary cold cathodes, being only limited by the heat developed by the discharge. The pressure of operation is so small that it can be obtained from any ordinary electric supply. The gas or vapour inside the gaseous lamp must emit a suitable spectrum and it must not decompose under the action of the discharge.

There are several other conditions the tube must fulfil. It has been found that a white light can be obtained from a neon tube provided a definite small 